\title{
SÍMBOLO CONTÁBIL: UM ESTUDO COM OS ACADÊMICOS DE CIÊNCIAS CONTÁBEIS DA UNEMAT-CÁCERES.
}

\author{
Pâmela Gabriela Ramos ${ }^{1}$ \\ Thaína Dornelas da Silva ${ }^{2}$
}

\section{RESUMO}

Este artigo foi elaborado a partir de pesquisa realizada com o corpo discente de um curso de Ciências Contábeis e ainda com pesquisas bibliográficas, visando elucidar o símbolo Caduceu na contabilidade e a importância em conhecê-lo. A partir da mitologia grega compreender-seá da melhor forma, o sentido, o significado e o porquê este símbolo vem a representar a profissão contábil, bem como apurar dos acadêmicos do curso de Ciências Contábeis até onde vai o seu entendimento pelo Caduceu. E dessa forma, fazer conhecer, cada elemento e o significado que esta simbologia representa, sendo a mesma formada por: um bastão, duas serpentes, o elmo e as asas.

Palavras- chave: Símbolo Contábil, Caduceu e Acadêmicos.

\section{INTRODUÇÃO}

Desde os primórdios da humanidade o homem se utiliza das manifestações gráficas, principalmente como meio de comunicação. Nesse contexto encontram-se os símbolos, que representam e expressam ideias, crenças, mitos, fatos ou situações que elucidam a realidade, sejam elas no âmbito pessoal ou profissional (citam-se os símbolos representativos da profissão)

Tratando-se da Ciência Contábil, a sua maior representação é o Caduceu, que também é conhecido como símbolo de Mercúrio, Deus protetor dos comércios. O patrimônio cultural da contabilidade, o Caduceu, tem uma história que está diretamente relacionada com a relevância da profissão contábil, cada detalhe e item que o compõe demonstra o papel, a ação, os cuidados, a agilidade e a dedicação necessária para se tornar um bom profissional e acima de tudo ético, pois as missões que são concedidas a um contador são de total sigilo e confiança

Diante do exposto surge a problemática: Qual o nível de conhecimento dos acadêmicos do $5^{\circ}$ ao $8^{\circ}$ semestre do Curso de Ciências Contábeis da Unemat (Universidade do Estado de Mato Grosso), Campus Cáceres no que refere-se ao símbolo da Contabilidade?

Partindo desse pressuposto a pesquisa apresenta o seguinte objetivo: analisar o conhecimento dos acadêmicos do curso de Ciências Contábeis quanto ao símbolo da profissão Contábil.

\footnotetext{
${ }^{1}$ Pós-Graduanda em Gestão Pública, Docente na Universidade do Estado de Mato Grosso. Rua São José, n 02 , Cavalhada II. CEP: 78200-000. E-mail: pamela.tutoriauab@gmail.com.

${ }^{2}$ Graduada em Ciências Contábeis pela Universidade do Estado de Mato Grosso. Rua São Francisco, n 200, Cavalhada II. CEP: 78200-00. E-mail: thaina.ds2@ hotmail.com.

\begin{tabular}{ll}
\hline Volume 3, Número 5 & Revista UNEMAT de Contabilidade
\end{tabular}

Jan./Jun. 2014

UNEMAT
} 
O trabalho justifica-se no interesse dos autores e na contribuição que este pode proporcionar aos cursos de graduação de Ciências Contábeis quanto ao símbolo da Contabilidade.

\section{REFERENCIAL TEÓRICO}

Para melhor entendimento sobre o Caduceu, necessário se faz voltar na história antiga e medieval, mais precisamente à mitologia Greco - Romana. Para Arruda (1587), a mitologia são lendas de aventuras dos deuses e dos heróis que são contadas e as chamamos de mitos, Peixoto (2003) acrescenta que, a mitologia é o conjunto de mitos que pertencem a um povo, a uma civilização, a uma comunidade, ressaltando que o conjunto dos mitos dá origem a mitologia e Mytos (mitos), vocábulo grego que significa "palavra", "fala", "conto", ou "história". Arruda (1587, p.165) ainda observa que a mitologia tem certa ligação com a religião, devido a esses mitos. Os fiéis da religião grega não tinham obrigações de crer em determinadas verdades, imaginariam como bem entendessem a vida após a morte, sem dogmas.

São muitos os mitos sobre deuses gregos, por isso a mitologia é um resultado de muita imaginação e crenças. Quanto à simbologia Contábil, diretamente ligada ao deus Grego Mercúrio, sendo este originário da mitologia grega romana. Este deus era filho de Júpiter (Zeus) e de Maia. Pelos gregos, Mercúrio era conhecido como Hermes, que tem como significado interprete ou mensageiro. E em latim seu nome vinha da palavra mercês, mercadoria.

A divindade máxima atribui-lhe também várias funções, devido a sua extrema habilidade. Cuidava desde os interesses do Céu, da Terra e do Inferno. Além de protetor dos viajantes, comerciantes, pastores (de gado), Hermes tinha o dom de bem falar e tinha uma participação considerável no conselho dos deuses. Conforme, Commelin (1997):

Ele não só contribuía para o desenvolvimento do comércio e das artes, como também se dizia que fora ele quem, em primeiro lugar, formara uma língua exata e regular, quem regulara a harmonia das frases, quem pusera nome a uma infinidade de coisas, quem instituíra praticas religiosas quem multiplicara e fortalecera as relações sociais, quem ensinara o dever aos esposos e aos membros da mesma família. Ensinara também aos os homens a luta e a dança, e em geral, todos os exercícios do estádio que necessitam de força e graça. Finalmente, foi o inventor da lira, à qual deu três cordas, que tornou - se instrumento de Apolo. COMMELIN (1997, p.56) 
Mercúrio presenteou seu irmão Apolo, deus do sol e da profecia, dando-lhe a lira, que generosamente retribuiu com um bastão mágico. Zeus, nesse momento, designou Mercúrio como mensageiro dos deuses por observar suas inúmeras qualidades.

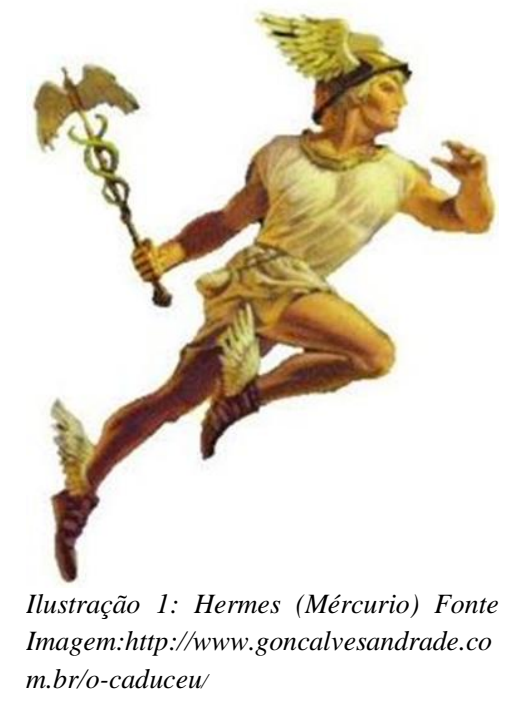

Mercúrio tinha como característica as asas no capacete e algumas vezes nos pés, que lhe trazia agilidade, ligeireza na execução das ordens que lhe era dada. Com o bastão mágico sempre em mãos, chamado de Caduceu, era o que o auxiliava no poder de adivinhação e proteção em suas missões divinas. Com isso, este, tornou - se símbolo de tudo que ele protegia como é o caso do comércio.

Quanto à profissão contábil, foi escolhido o Caduceu (CFC. 2003) em razão das afinidades entre as atividades comerciais e o trabalho contábil, e também porque o próprio sistema de afirmação das partidas dobradas dar-se-ia a partir do século XI, quando, na Europa, o comércio ditaria a nova fase da vida nas capitais.

Conforme CRC/BA (2005):

\begin{abstract}
Em Portugal (século XVIII) quando se iniciou o ensino da Contabilidade, em escolas onde se formavam os Contadores que vinham para o Brasil o processo didático denominava-se "Aulas de Comércio". Ainda hoje possuímos os colégios comerciais, formando técnicos em Contabilidade. Essa poderosa associação de "Aulas de Comércio", "Escolas Técnicas de Comércio", "Escrita Mercantil", "Livros Comerciais" (expressões do Direito), justifica a adoção de Mercúrio, como evocação representativa, e do caduceu representante simbólico desse mesmo Deus como símbolos da Contabilidade. O caduceu, todavia, por muito tempo, também simbolizou a indústria, e foi representado por um ramo de oliveira ou de loureiro no qual se enrolavam duas serpentes. (CRC/BA p. 01, 2005)
\end{abstract}

Com tudo, Mercúrio era visto também como o deus inventor da Escrita Contábil e o Caduceu é o principal símbolo que o representava, que tem como significado o poder, conhecido 
também como "bastão de arauto".

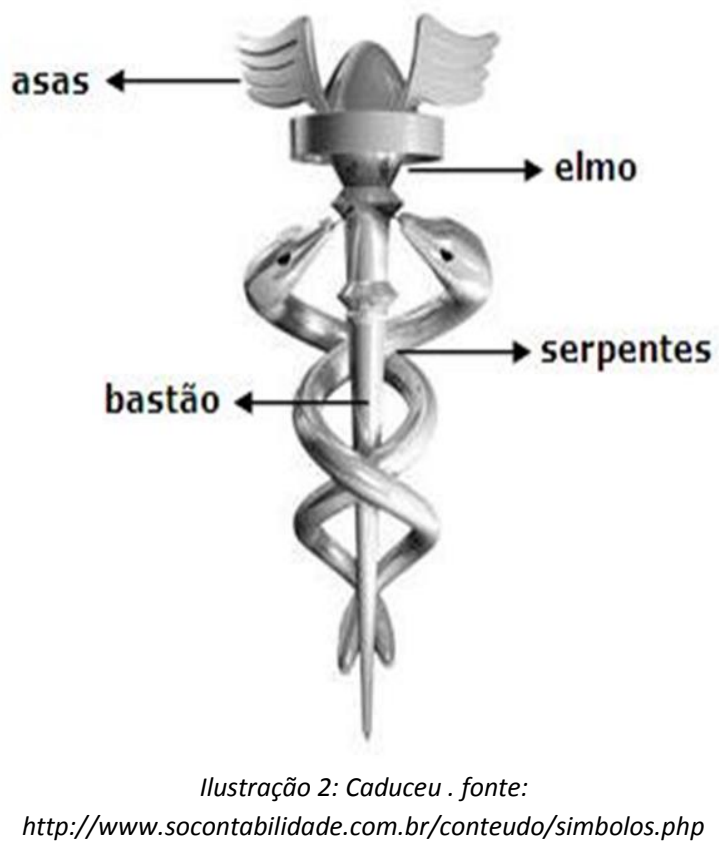

Como símbolo contábil, o Caduceu é formado por um bastão envolvido por duas serpentes, além de apresentar também asas e o elmo. Segundo a obra Mensagem a um futuro contador (CFC, 2003), este "bastão é uma figuração de um ramo vigoroso de loureiro, planta mística que segundo os gregos, protegia os lares, pois os raios não atingiam jamais tal planta, além de ela ter rara virtude medicinal e um odor apreciado". Afirma também que "o louro gerava coroas que encimavam a cabeça dos heróis. A famosa coroa de louro era o símbolo do vitorioso; daí a importância da figuração.”

Outros autores diz-se que o bastão citado seria de ouro, e serviu para tanger o gado de Apolo, sendo a origem do próprio negócio do caduceu. De acordo com o historiar Higino, quando Hermes passava por Arcádia, uma região da Grécia encontrou duas serpentes enroladas brigando e Hermes para separá-las usou o caduceu e elas ficaram entrelaçadas nele. Segundo o historiador, esse é um dos aspectos de Hermes a diplomacia e quem sabe isso tenha a ver com o equilíbrio também.

A obra anteriormente citada (CFC, 2003) comenta também, que as serpentes entrelaçadas no bastão são para demonstrar o elo entre os atributos de natureza humana, social e profissional. Simbolizam a sabedoria, isto é, o quanto se deve estudar antes de agir, para escolher o caminho correto e ao mesmo tempo o mais vantajoso para o cliente.

Também é interpretada por outros autores como a representação do percurso da energia no corpo humano, assim como se postam as serpentes, a energia termina na cabeça, 
sede de toda a concentração vital. Esotericamente, de acordo com a energia Kundalini, as duas serpentes opostas figuram forças contrárias que podem se associar, mas não confundir. $\mathrm{O}$ bastão do caduceu corresponde ao eixo do mundo e as serpentes, para o historiador Alemão Schneider, que formam os dois " $\mathrm{S}$ " correspondem a doença e a convalescença.

As asas por sua vez, simbolizam a velocidade do deus Hermes, que figura a diligência, a presteza, a dedicação e o cuidado ao exercer a profissão. No Caduceu as asas estão inseridas no capacete. Em outras figuras, nos calcanhares de Mercúrio.

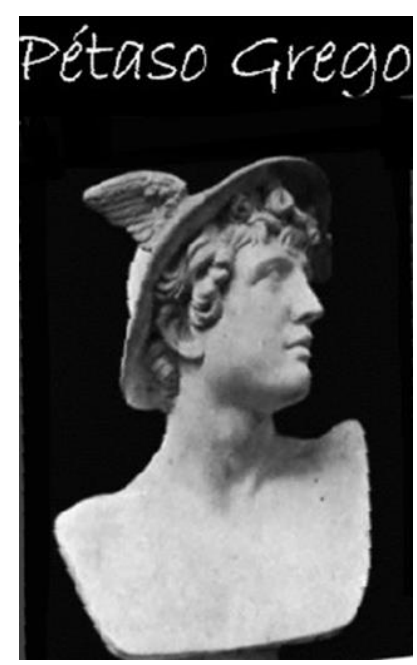

Ilustração 3: Pétaso. Fonte: http://blogbeiramarshopping.com.b $r /$ citennun/Ptan=rhaneli

O Elmo é uma peça de armadura antiga (capacete) que protegia a cabeça, tem predominância de pensamentos elevados, ou seja, tem significado de proteção contra pensamentos baixos que levem a ações desonestas. Hermes possuía um, que também era chamado de Pétaso. Este o tornava invisível e lhe permitia avaliar atitudes e exercer controles, com extremos poderes sobre a ação de todos.

Contudo, pode - se dizer que o patrimônio cultural da contabilidade, o Caduceu, para o curso de Ciências Contábeis traz como representação, o bastão, como a graduação, sendo também interpretado como a espinha dorsal do curso, ou seja, a capacitação para o exercício da profissão. As serpentes é a extensão, como também vem a representar a integração das matérias e atividades de formação profissional básica, específica e complementar. As asas é a pesquisa e o elmo é a comunicação e representa também dentro do currículo pleno curso de Ciências Contábeis, a ética geral e profissional.

Para o profissional contábil, o bastão vem simbolizar o poder de quem conhece a Ciência Contábil, que tem por objeto o patrimônio de quaisquer entidades. As Serpentes Volume 3, Número 5 Revista UNEMAT de Contabilidade 
simbolizam a sabedoria, isto é, o quanto se deve estudar antes de agir, para escolher o caminho correto e ao mesmo tempo mais vantajoso para o cliente. As Asas simbolizam a diligência, ou seja, a presteza, a solicitude, a dedicação e o cuidado ao exercer a profíssão, e o Elmo representa a proteção aos pensamentos baixos, para que não leva a ações desonestas.

Assim, com um breve histórico de Hermes e seu Caduceu, podemos identificar tais semelhanças quanto à simbologia da contabilidade, mesmo que na mitologia que é visto como resultado de muita imaginação e crenças, trás consigo uma mensagem aos profissionais como respeitar e fazer respeitar o símbolo de sua profissão.

\section{METODOLOGIA}

Quanto à natureza, este é primordialmente qualitativo, se utilizando de ferramentas quantitativas. Qualitativa por que será analisado o conhecimento dos acadêmicos quanto ao símbolo da Contabilidade, Beuren (2004, p. 92) ressalta que, na pesquisa qualitativa concebem-se análise mais profunda em relação ao fenômeno que esta sendo estudado, sendo uma forma adequada para conhecer a natureza de um fenômeno social. Já a abordagem quantitativa caracteriza-se pelo emprego de instrumentos estatísticos, tanto na coleta quanto no tratamento dos dados.

Quanto ao objetivo, se caracteriza como descritiva, pois tem como objetivo identificar o nível de conhecimento dos acadêmicos quanto ao símbolo da Contabilidade. Segundo Beuren (2004) a pesquisa descritiva ter como característica observar os fatos e analisá-los sem se intrometer-se nele.

Esta pesquisa se caracteriza por estudo de caso, onde serão analisados os conhecimentos dos acadêmicos referentes ao símbolo Contábil. Segundo Beuren (2004) a pesquisa de estudo de caso se caracteriza principalmente pelo estudo de um único caso. Esse estudo é preferido pelos pesquisadores que desejam aprofundar seus conhecimentos a respeito de determinado caso especifico.

Para a coleta dos dados, utilizou-se questionários, com perguntas semiestruturadas. Quivy e Campenhoudt (1998) consideram que o questionário é uma técnica de observação direta, extensiva, especialmente adequada para conhecer determinadas características de uma população ou estudar fenômenos sociais. Segundo Beuren (2004):

O questionário é um instrumento de coleta de dados constituído por uma serie ordenada de perguntas que devem ser respondidas por escrito pelo informante, sem a 
presença do pesquisador. Devem ser claro e limitado em extensão e estar acompanhado de notas que expliquem a natureza da pesquisa e ressaltem a importância e necessidade das respostas, a fim de motivar o informante. BEUREN, 2004, p. 130).

Gil (1999) define o questionário como uma técnica de investigação composta por um número de questões apresentados por escrito às pessoas, com objetivo o conhecimento de suas opiniões.

A coleta foi feita no dia 16 de agosto de 2013, no Campus Universitário Jane Vanini, no turno matutino com visita in loco, onde o autor se identificou, explicou o teor da pesquisa, instruiu os participantes e aplicou os questionários.

\subsection{Análises dos dados}

Devido a estrutura do questionário com questões abertas e fechadas, os dados foram analisados em 2 (dois) momentos distintos. As perguntas fechadas foram analisadas através do software (StatisticPackage Social Science - SPSS 13.0). Conforme o Manual de Utilização do SPSS, este se configura como um software apropriado para a elaboração de análises estatísticas de matrizes de dados. $\mathrm{O}$ seu uso permite gerar relatórios tabulados, gráficos e dispersões de distribuições utilizadas na realização de análises descritivas e de correlação entre variáveis.

Com relação as perguntas abertas estas foram analisadas através da análise de conteúdo proposta por Bardin (1977), conforme Moraes (1999) esta metodologia consiste em descrever e interpretar todo e qualquer conteúdo referente a documentos e textos.

\section{RESULTADOS}

Visando responder o objetivo proposto, foi aplicado um questionário contendo 5 (cinco) perguntas ao acadêmicos do $5^{\circ}$ (quinto) ao $8^{\circ}$ (oitavo) semestre do curso de Ciências Contábeis da Unemat, campus Jane Vanini, Cáceres-MT. O questionário foi construído de forma semiestruturada, com questões objetivas e subjetivas, na busca de identificar e analisar o conhecimento dos acadêmicos sobre o Símbolo da Contabilidade.

Gil (1999) define o questionário como uma técnica de investigação composta por um número de questões apresentados por escrito às pessoas, com objetivo de conhecer suas opiniões. A análise das mesmas foi feita como seguem. 
A primeira pergunta teve como finalidade descobrir se os acadêmicos sabem qual o nome do símbolo da contabilidade. Satisfatoriamente mais da metade da população disse que sabe o nome do símbolo. Em análise mais detalhada, percebe-se que o $6^{\circ}$ (sexto) semestre apresenta o melhor índice, onde 13 (treze) entrevistados disseram que conhece, contra 4 (quatro) que desconhecem. Fato curioso se destaca no $7^{\circ}$ (sétimo) semestre, onde 7 (sete) acadêmicos disseram conhecer e 8 (oito) disseram não conhecer o nome do símbolo. Esse fato pode ser justificado pela disciplina que estava sendo lecionada no momento da pesquisa, onde se encontram acadêmicos que não são regularmente matriculados no semestre em questão.

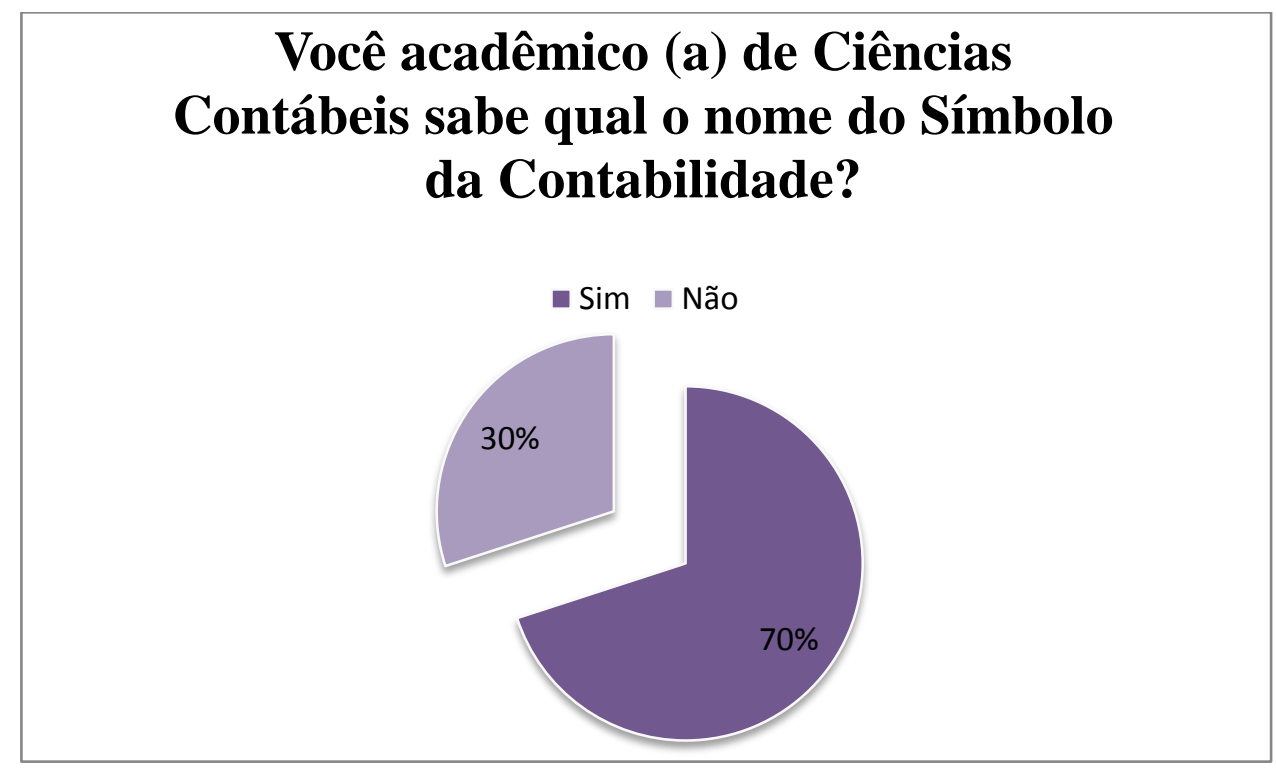

Fonte: o autor (2014)

Importante também ressaltar que dentre os entrevistados, no universo de respondentes que sim, ou seja, que sabem o nome do símbolo da contabilidade, 10 (dez) acadêmicos não colocou o nome do mesmo. Diante disso, o gráfico abaixo apresenta o percentual de pesquisados que citaram o nome do Caduceu como Símbolo da Contabilidade. 


\section{Qual o nome do Símbolo?}

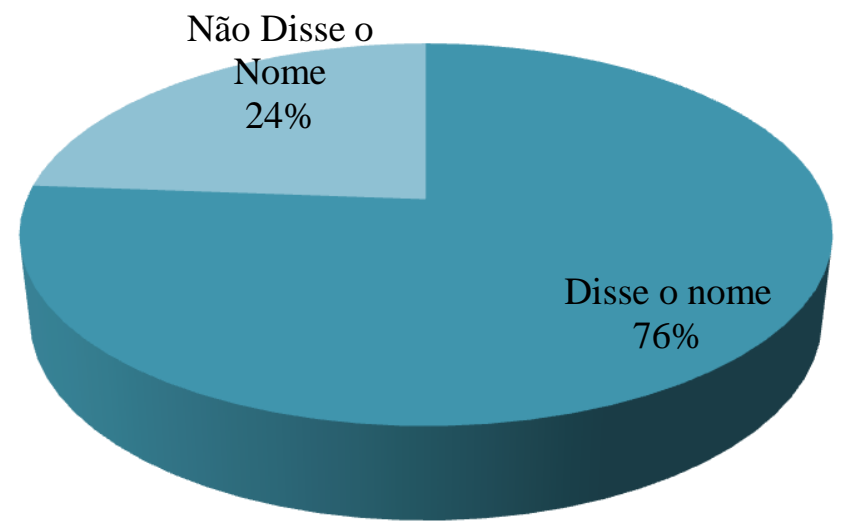

Fonte: o autor (2014)

Visando conhecer se em alguma disciplina ou momento do decorrer do curso foi abordado/explicado sobre o símbolo da contabilidade, os resultados não são tão favoráveis, a maioria dos entrevistados disseram que não viram o tema na universidade. Ressalta-se a fala de um acadêmico "Não, porém pesquisei para obter mais informações. Nenhum professor nos explicou sobre esse símbolo". Outro acadêmico aponta que no $1^{\circ}$ semestre foi abordado o tema, porém, apenas o nome.

\section{Em alguma disciplina ou momento no decorrer do curso foi abordado/explicado o Símbolo da Contabilidade?}

Fonte: o autor (2014) 
Quando questionados em qual disciplina, apenas duas são citadas, sendo elas Contabilidade Geral I, sendo esta a mais citada, e Teoria da Contabilidade, sendo disciplinas do $1^{\circ}$ (primeiro) e $5^{\circ}$ (quinto) semestre respectivamente.

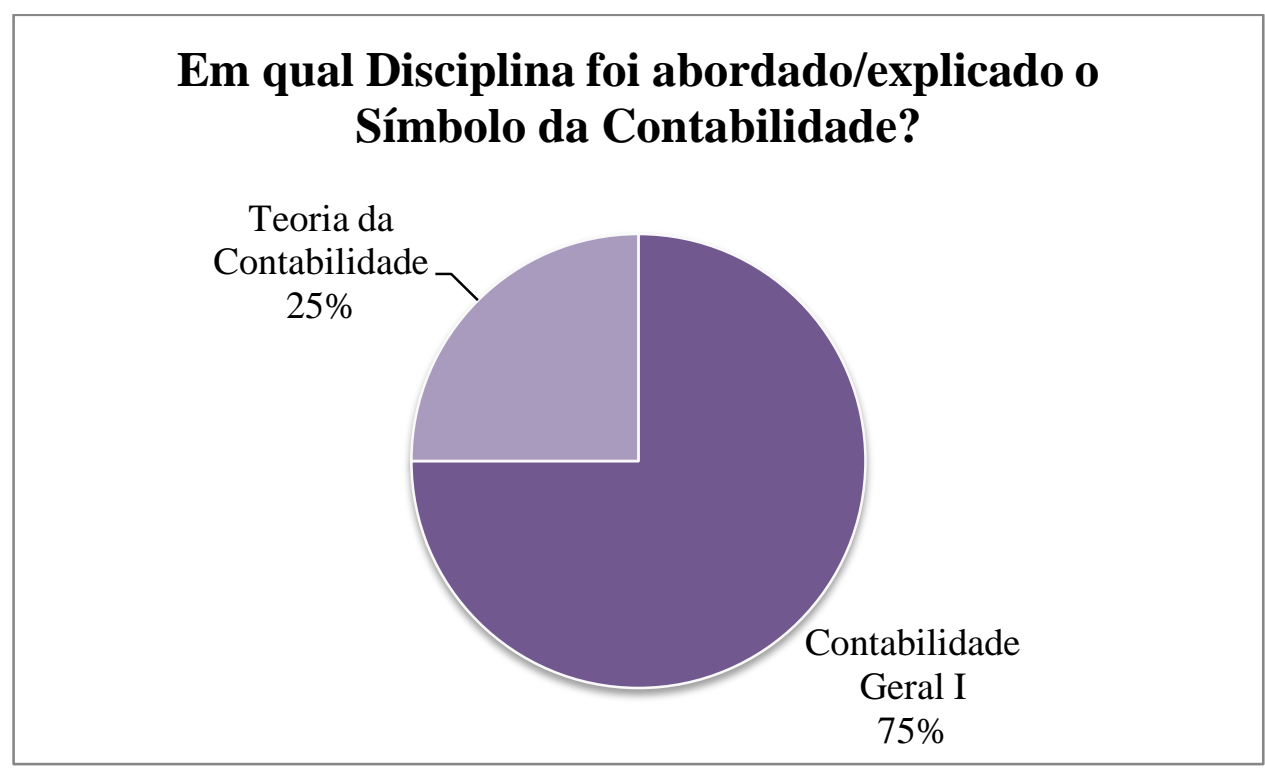

Fonte: o autor (2014)

Dos 15 (quinze) entrevistados que citou a disciplina de Contabilidade Geral I, 10 (dez) eram entrevistados do $8^{\circ}$ semestre, deduzindo que no ano em que adentrou na Universidade, a disciplina abordou o tema.

Importante verificar também se os acadêmicos conhecem os itens que compõem o símbolo e o que cada um significa. Nesse contexto, os acadêmicos que conhecem o símbolo estariam aptos a responder a pergunta, porém os resultados apontam que; $7 \%$ conhecem alguns itens somente, onde repetidamente citaram o Bastão e a Serpente, $11 \%$ disseram que conhecem, porém 2 entrevistados não descreveram os itens e 5 citaram todos os itens; Asas, Elmo, Bastão e Serpente e $82 \%$ responderam que não sabem quais os itens, onde 8 (oito) acadêmicos responderam que não lembram. 


\section{Você conhece quais os itens compõem o Símbolo da Contabilidade e o que cada um significa?}

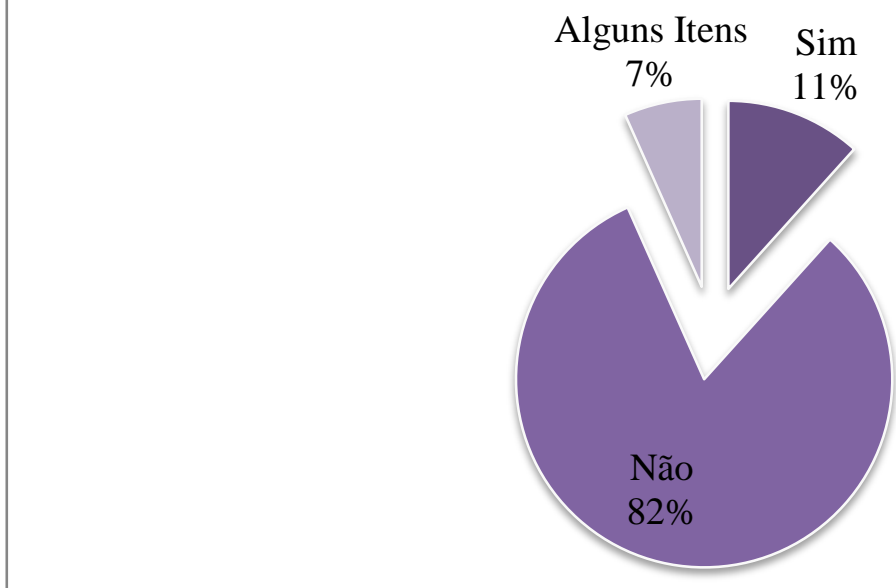

Fonte: o autor (2014)

Quando analisada a pergunta, cuja resposta fosse completa, dos 7 (sete) entrevistados que disseram conhecer os itens, apenas 5 (cinco) descreveram completo e corretamente a pergunta, diante dos dados, percebe-se que somente $8 \%$ do total de 60 entrevistados conhecem os itens do símbolo da contabilidade e o seu significado.

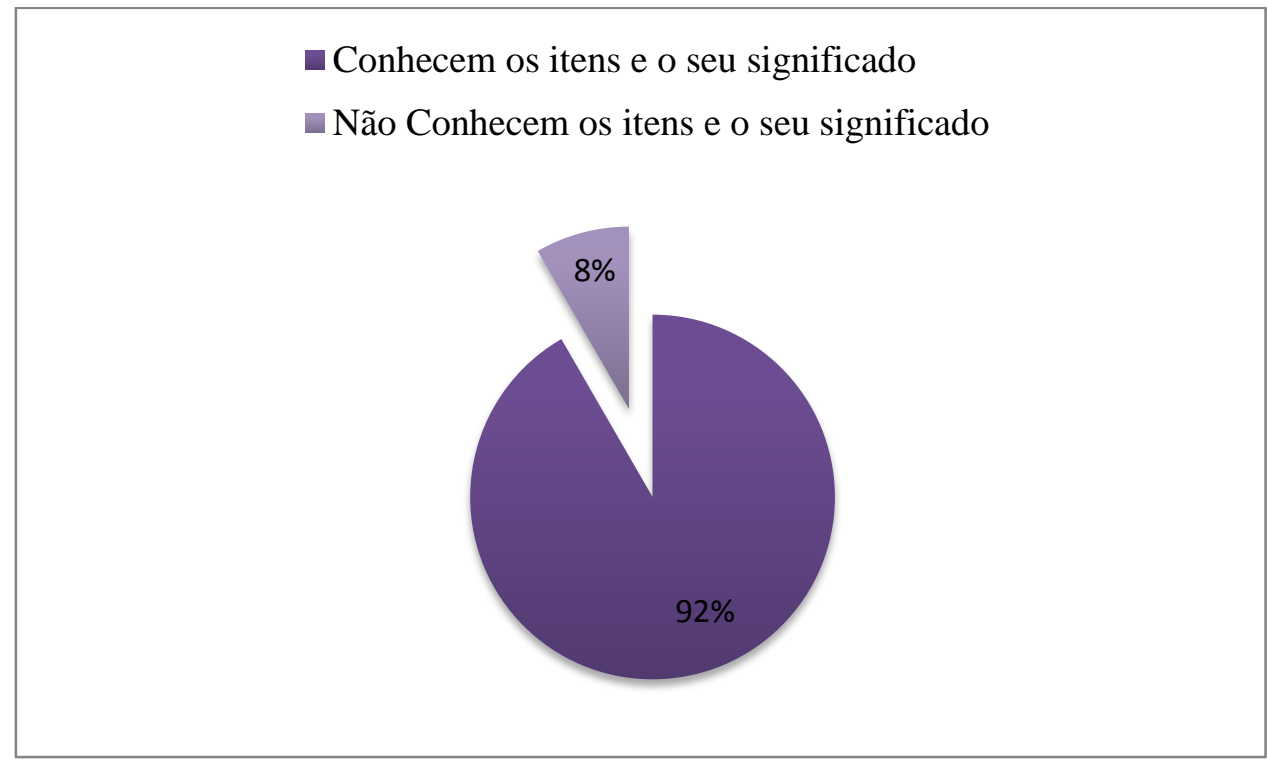

Fonte: o autor (2014). 
A última pergunta foi aberta, visando conhecer a visão dos acadêmicos quanto à relevância da abordagem e explicação do símbolo da contabilidade na graduação. As análises desses dados foram feitas através da análise de conteúdo proposta por Bardin (1977).

Dentro do contexto de relevância e abordagem do símbolo no curso de Ciências Contábeis, dos 60 (sessenta) entrevistado, apenas 2 (dois) disseram não ser relevante essa abordagem do símbolo da Contabilidade. Porém, análise de conteúdo foi feita com base nas respostas da grande maioria.

O termo conhecimento aparece repetidamente na fala dos acadêmicos, os mesmos apontam que é fundamental conhecer profundamente o símbolo, relacionando-o diretamente ao exercício da profissão. Segue algumas justificativas dos entrevistados do $5^{\circ}$ (quinto) semestre:

\footnotetext{
"Sim, pois o profissional que se preze, tem que saber tudo relacionado a sua profissão".

"Sim, pois se for perguntado a nós contadores a respeito do símbolo da contabilidade, saibamos responder de forma correta e sábia."

"Sim. Tudo aquilo que é criado, tem um motivo, relacionado a fatos e acontecimentos......"
}

Nos $6^{\circ}$ (sexto) e $7^{\circ}$ (sétimo) semestre, os acadêmicos não foram incisivos nas respostas, aparecem os termos conhecimento no contexto geral. Ressalta-se a fala de um entrevistado, afirmando que em nenhum momento foi passado ao mesmo o símbolo do curso e que também não teve a curiosidade de perguntar, porém, conclui que, gostaria sim de saber sobre o símbolo. Outro pesquisado considera importante a abordagem do tema, para que, quando questionado possa responder detalhadamente sobre o significado do símbolo para a contabilidade.

Os acadêmicos do $8^{\circ}$ (oitavo) semestre foram enfáticos nas respostas, associando a relevância da abordagem do símbolo a diversos fatores, dentre eles, a sua importância no que se refere à história da contabilidade "o símbolo faz parte da história da contabilidade, temos que estar por dentro do assunto", diz um entrevistado, outro afirma que "tal explicação é necessária por que estão vinculadas as bases da profissão contábil, não é apenas um símbolo, possui muita história".

Nessa questão não houve alternância de fatores, aparecendo repetidamente os termos profissão e história da contabilidade. Diante dos dados, percebe-se que, os acadêmicos possuem conhecimentos básicos sobre o tema, assim como reconhecem a importância da abordagem do símbolo. 


\section{COSIDERAÇÕES FINAIS}

O Caduceu, símbolo da contabilidade vem realçar e destacar os valores e atitudes do bom profissional, assim como enaltece a profissão Contábil. Porém, mesmo diante desse contexto de relevância do tema, o mesmo, por diversas vezes, não é abordado nos cursos de graduação. Os resultados da pesquisa aponta o atual cenário de conhecimento dos acadêmicos do $5^{\circ}$ ao $8^{\circ}$ semestre do curso de Ciências Contábeis da Unemat-Cáceres no que se refere ao Símbolo Contábil.

A pergunta primordial sobre o nome do símbolo apresentou um bom resultado, grande parte dos entrevistados citaram o nome "Caduceu", entretanto quando questionados sobre os elementos que o compõem, apenas 5 acadêmicos elencaram todos os itens, 4 lembraram do Bastão e da Serpente e a maioria disse não conhecer a composição do símbolo.

Quando questionados sobre em qual disciplina ou momento foi abordado o tema, as respostas apontam a disciplina de Contabilidade Geral I, lecionada no $1^{\circ}$ semestre, onde há relatos de que a abordagem foi referente apenas ao nome, justificando de certa forma o não conhecimento dos acadêmicos quanto aos elementos que formam o símbolo contábil.

Em um último momento, no que se refere a relevância da abordagem e explicação do símbolo, percebe-se que os acadêmicos reconhecem a necessidade de estudar e conhecer o Caduceu, pautados na importância deste para a profissão, relacionando-o diretamente ao conhecimento empírico da Contabilidade e todo seu contexto histórico.

Conclui-se diante do exposto, que os participantes da pesquisa possuem um nível de conhecimento básico sobre o símbolo Contábil.

A pesquisa é de fundamental importância, para que a partir dos resultados, os docentes dos cursos de graduação em Ciências Contábeis possam estabelecer metodologias de abordagem do símbolo contábil, propiciando aos acadêmicos conhecimentos sólidos inerentes a profissão.

Como sugestão para futuros estudos, sugere-se a abordagem de todos os símbolos ligados a profissão contábil, complementando o presente estudo.

\section{REFERÊNCIAS BIBLIOGRÁFICAS}

A Responsabilidade Técnica e Social do Contador na Organização - revista ciências contábeis $\mathrm{n}^{\mathrm{o}} 5$ - maio de 2008. Faculdades novos horizontes . pg 21 
BEUREN, Ilse Maria. Como elaborar trabalhos monográficos: teoria e prática. 2. ed. São Paulo: Atlas, 2004.

Caduceu. Disponível em: . http://www.borkenhagen.net/caduceu.html. Acesso em: 19 ago. 2014.

Caduceu. Disponível em: http://www.goncalvesandrade.com.br/o-caduceu.html. Acesso em: 14 ago 2014.

CFC. Código de Ética Profissional do Contabilista. Brasília, 2000.

COMMELIN. P. Nova mitologia grega e romana. Editora Itatiaia Ltda. Belo Horizonte, 1997.

CONSELHO FEDERAL DE CONTABILIDADE - CFC. Mensagem a um futuro contabilista. $-7^{\mathrm{a}}$ Ed - Brasília: CFC, 2003. 60 p. 40p, 41p

GIL. Antônio Carlos. MÉTOdOS E TÉCNICAS DE PESQUISA SOCIAL. 5.ed.São Paulo:Atlas, 1999.

História do Caduceu. Disponível em: http://www.crcba.org.br/boletim/edicoes/2005_10_21.htmL. Acesso em: 12 ago. 2014.

Imagem do Caduceu. Disponível em: http://www.socontabilidade.com.br/conteudo/simbolos.php. Acesso em: 23 ago. 2014.

Imagem Hermes. Disponível em: http://www.goncalvesandrade.com.br/o-caduceu/. Acesso em: 23 ago. 2014.

Manual do SPSS. Disponível em: http:// docentes.ismt.pt/ m_pocinho/manual_SPSS.pdf. Acesso em: 25 ago. 2014.

MORAES, R. Análise de conteúdo. Revista Educação, Porto Alegre, 1999. 